\title{
Transformation of Gear Inter-Teeth Forces into Acceleration and Velocity*
}

\author{
WALTER BARTELMUS ${ }^{\dagger}$ \\ Wroctaw University of Technology, Faculty of Mining, Machinery System Division, Pl. Teatralny 2 50-051 Wroclaw, Poland
}

(Received 23 April 1998; In final form 10 July 1998)

\begin{abstract}
The paper deals with mathematical modelling and computer simulation of a gearbox system. Results of computer simulation show new possibilities of extended interpretation of a diagnostic acceleration signal if signal is obtained by synchronous summation. Four groups of factors: design, production technology, operation, change of gear condition are discussed. Results of computer simulations give the relation between inter-teeth forces and vibration (acceleration, velocity). Some results of computer simulations are referred to the results obtained in rig measurements and in field practice. The paper shows a way of increasing the expert's knowledge on the diagnostic signal, which is generated by a gearbox system, on a base of mathematical modelling and computer simulation.
\end{abstract}

Keywords: Gearing diagnostic, Vibration, Computer simulation, Condition factors, Inter-teeth forces

\section{INTRODUCTION}

Mathematical modelling and computer simulation give new possibilities of investigating the vibration diagnostic signals generated by a gearing of gearbox system for aiding diagnostic inference. In Bartelmus (1994, 1996, 1997), relations between condition of the gearing and inter-teeth forces are given. It comes from that the results of computer simulations were referred to results obtained by measurements presented in Rettig (1977). Because the diagnostic assessment of the gearing condition is taken from vibration measurements, the presented paper is mainly concentrated on relation between inter-teeth forces and vibration parameters like acceleration and velocity. Simulations may be done for any conditions which may change the vibration diagnostic signal. Gear conditions under which investigations were done by Rettig were limited to the change of the operation caused by the change of rotation speed of gears. The gear conditions may be described, as stated in Bartelmus (1992), by four groups of factors: design, production technology, operation, change of gear condition. Many factors will be taken into consideration and results of computer simulations given by the

* This paper was originally presented at ISROMAC-7.

${ }^{\dagger}$ Tel.: 4871441201 . Ext.: 406. Fax: 4871448123. 
relation between inter-teeth forces and vibration (acceleration, velocity) will be presented. First mathematical model of a gear system taken into consideration design, production technology, operation and change of condition was given in Bartelmus (1994). The mathematical model is constantly developed and by the use of computer simulations different aspect of gear system dynamics are investigated (Bartelmus, 1996; 1997). The results of computer simulations are referred to the results obtained by a rig investigation (Rettig, 1977) and a field investigation (Bartelmus, 1988; 1992). The results obtained by Rettig (1977) are given in Fig. 1. A dynamic factor giving as a ratio $K_{\mathrm{d}}=$ $F(t) / F$ against a length of line of action, expressed by $\%$ of the length, is given. A gear system may run under resonance and over-resonance. The gear system operates at resonance when a meshing frequency equals to a natural frequency of a gearing. Results of computer simulations are given in Figs. $2-4$. In Fig. 2 the result of computer simulation is given for the gearing operation under resonance run. It is easy to see similarities obtained by measurements and computer simulations, compare Fig. 1 with Fig. 2, run under resonance. A result of computer simulation when gearing runs at resonance is given in Fig. 3. In Fig. 3 one can see a

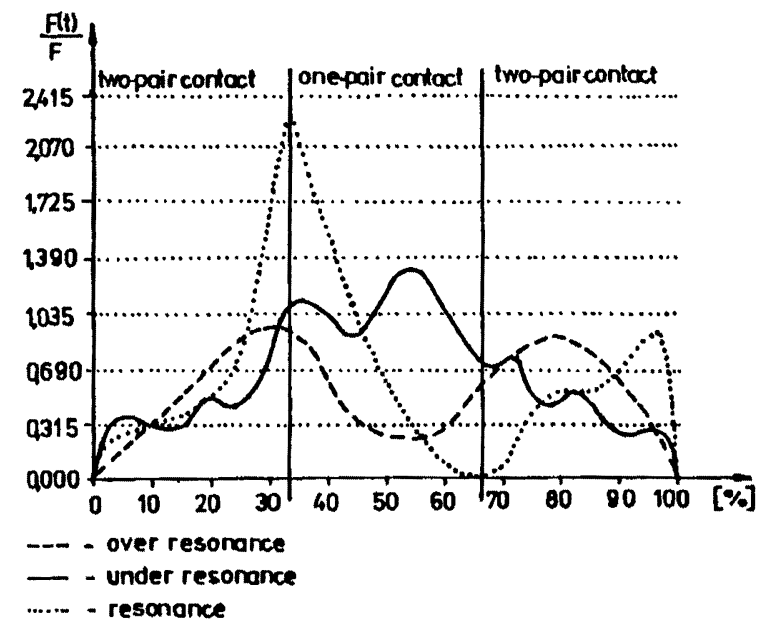

FIGURE 1 Results of measurements of inter-teeth forces (Rettig, 1977).

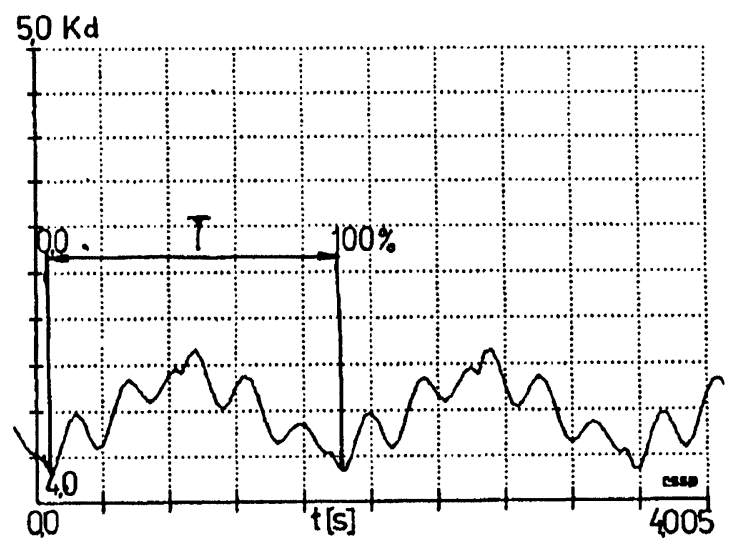

FIGURE 2 Function of gearing dynamic factor $K_{\mathrm{d}}$ for under resonance run of gearing (Bartelmus, 1996), $T$ - meshing period.

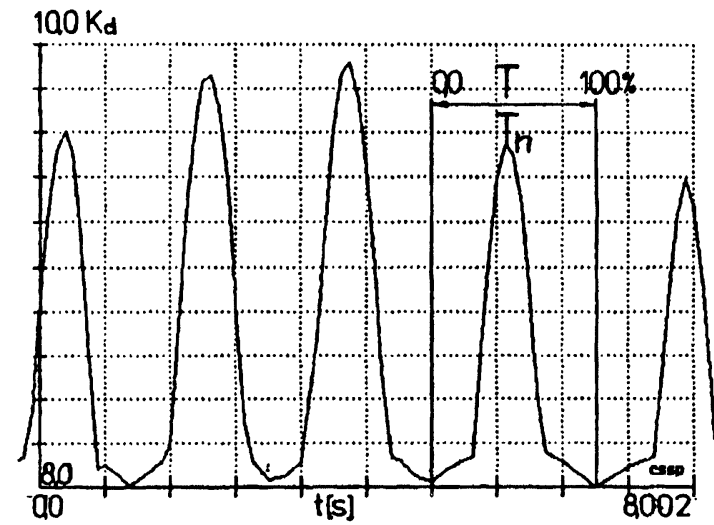

FIGURE 3 Function of gearing dynamic factor $K_{\mathrm{d}}$ for resonance run of gearing (Bartelmus, 1996), $T$ - meshing period, $T_{\mathrm{n}}$ - natural vibration period.

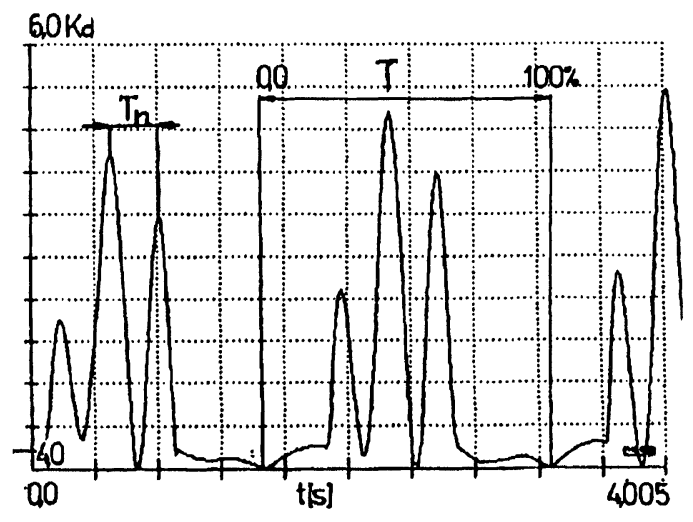

FIGURE 4 Function of gearing dynamic factor $K_{\mathrm{d}}$ for unstable run of gearing (Bartelmus, 1996), $T$ - meshing period, $T_{\mathrm{n}}$ - natural vibration period. 

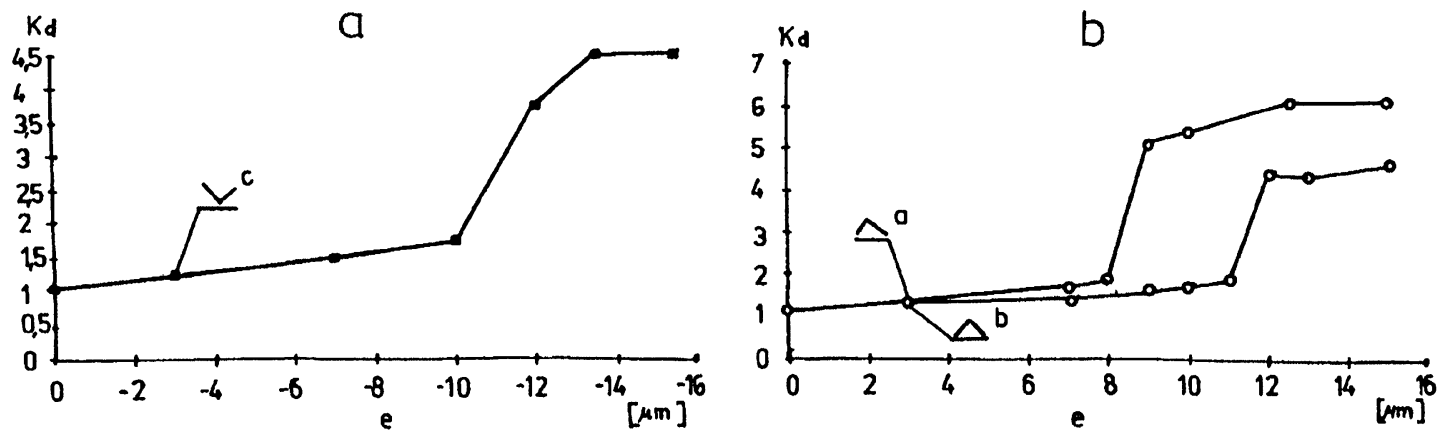

FIGURE 5 Gearing dynamic factor $K_{\mathrm{d}}$ as function of inter-teeth error and shape of error (Bartelmus, 1996), (a) error mode $(a ; e ; r)$ (parameter of error function; maximum value of error; coefficient of error change), $(0.1 ; e ; 0)$, (b) error mode for $(0.5 ; e ; 0)$, (c) error mode for $(0.5 ;-e ; 0)$.

distinct pick for one period of meshing the same as for a result taken from measurements (Fig. 1). Figures 1-3 describe the influence of operation factors to a signal generated by a gearing. The cooperation of a gearing depends also on the design and the change of condition factors given by errors of teeth. Figure 4 gives a result of computer simulation when a gearing runs at unstable conditions caused by tooth errors (Bartelmus, 1996). Figure 4 shows influence of a natural frequency to a course of inter-teeth forces. In Fig. 4 a period of a meshing $(0.0-100 \%)$ and period $T_{\mathrm{n}}$ of a natural frequency is given. Figure 5(a) and (b) shows courses of $K_{\mathrm{d}}$ against error $e(\mu \mathrm{m})$ and as the function of error shape, defined later. Presented results of computer simulations are also referred to the results presented in Penter (1991) where diagnostic signal is obtained by synchronous summation. An example of a vibration signal is given in Fig. 6 (Penter, 1991). The signal is given as a function of time $t(\mathrm{~s})$. It is the signal that shows a broken tooth in the gearing. Presented results of computer simulations may be considered as idealised results of synchronous summation.

\section{MODELLING OF GEARBOX SYSTEM}

As it was stated for modelling of dynamic properties of gear system: design, production technology,

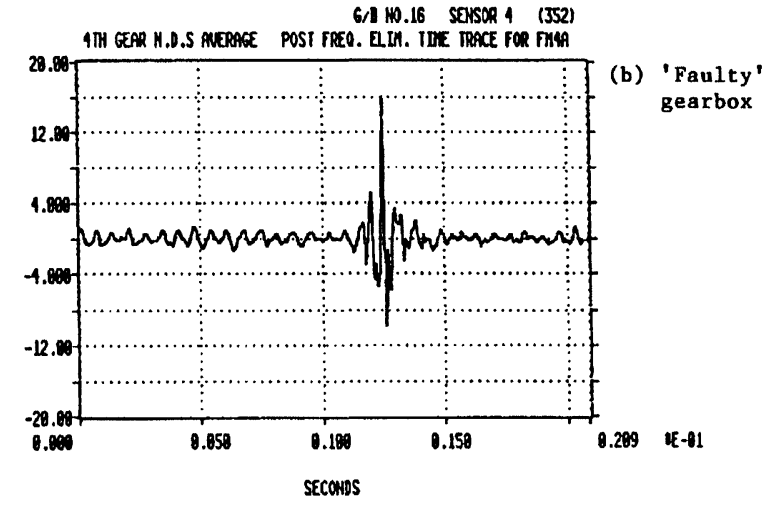

FIGURE 6 Diagnostic signal for broken tooth obtained by synchronous summation of signal (Penter, 1991).

operation, change of gear condition factors ought to be considered. Design factors include specified flexibility/stiffness of the gear components, especially flexibility/stiffness of a meshing, and a specified machining tolerance and errors of components.

Production technology factors include deviations from specified design factors obtained during machining and assembly of a gearbox.

Operational factors include peripheral speed (pitch line velocity) $v(\mathrm{~m} / \mathrm{s})$ and its change $\Delta v$ (m/s) and load $F$ and its change $\Delta F$.

Change of condition includes influences of gear wear, pitting, fractured or broken tooth. 
From simulation point of view in the considered gear system the design factors can be divided into two groups: constant and controlled. The constant design factors are not controlled/changed for different simulation experiments. The controlled design factors are changed before a specified simulation experiment. The constant design factors are given by: $I_{\mathrm{s}}, I_{1 \mathrm{p}}, I_{2 \mathrm{p}}, I_{\mathrm{m}}-$ moments of inertia $\left(\mathrm{kg} \mathrm{m}^{2}\right)$ (Fig. 7); $k_{1}, k_{2}$ - shaft stiffness coefficients (Nm/rad) (Fig. 7); $\mu$ - coefficient of inter-teeth friction; $C_{\mathrm{h}}-$ gearing damping coefficient $(\mathrm{N} \mathrm{s} / \mathrm{m}) ; r_{1}, r_{2}-$ base radii of gears $(\mathrm{m}) ; a, b, c$ - parameters of gearing stiffness $(0-1)$ (Fig. 8(a)); $l$ - inter-teeth backlash $\mu \mathrm{m}$; $C$ - maximum value of gear stiffness $(\mathrm{N} / \mathrm{m})$, $g$ - changeability of gearing stiffness $(0-0.4), 0.4$ for spur-gear. The controlled design factors are given by: $C_{\mathrm{s}}-$ clutch/coupler dumping coefficient $(\mathrm{Nm} \mathrm{s} / \mathrm{rad}) ; a, e_{1}$ - parameters of error function (Fig. 8(b)); $l_{i}$ - random coefficient of error $(0-1)$; $r$ - coefficient of error change (0-1), so a value of an error for a given tooth is expressed by

$$
e=\left[1-r\left(1-l_{i}\right)\right] e_{1},
$$

where $i$ - number of teeth pair; $l_{i}$ is distributed randomly for $z_{1}$ pair of teeth, number of teeth in the pinion of gears equals to $z_{1}, e_{1}$ maximum value of teeth error $(\mu \mathrm{m})$. The error of teeth may be described by error mode $\left(a ; e_{1} ; r\right)$. Mathematical model for torsion vibration for the system (Fig. $7(\mathrm{a}))$, is given by equations

$$
\begin{aligned}
I_{\mathrm{s}} \ddot{\varphi}_{1} & =M_{\mathrm{s}}\left(\dot{\varphi}_{1}\right)-\left(M_{1}+M_{\mathrm{h}}\right), \\
I_{1 \mathrm{p}} \ddot{\varphi}_{2} & =M_{1}+M_{\mathrm{h}}-r_{1}\left(F+F_{\mathrm{t}}\right)+M_{\mathrm{tz} 1}, \\
I_{2 \mathrm{p}} \ddot{\varphi}_{3} & =r_{2}\left(F+F_{\mathrm{t}}\right)-M_{2}-M_{\mathrm{tz} 2}, \\
I_{\mathrm{m}} \ddot{\varphi}_{4} & =M_{2}-M_{\mathrm{r}} .
\end{aligned}
$$

Values of forces and moments are given by

$$
\begin{aligned}
M_{1} & =k_{1}\left(\varphi_{1}-\varphi_{2}\right), \quad M_{2}=k_{2}\left(\varphi_{3}-\varphi_{4}\right), \\
M_{\mathrm{h}} & =C_{\mathrm{s}}\left(\dot{\varphi}_{1}-\dot{\varphi}_{2}\right) F-\text { Eq. }(4), \\
F_{t} & =C_{\mathrm{h}}\left(r_{1} \dot{\varphi}_{2}-r_{2} \dot{\varphi}_{3}\right),
\end{aligned}
$$

where $\varphi, \dot{\varphi}, \ddot{\varphi}$ - rotation angle, angle velocity, angle acceleration; $M_{\mathrm{s}}(\dot{\varphi})$ - electric motor driven moment characteristic; $M_{1}, M_{2}$ - moments of shafts stiffness; $I_{\mathrm{s}}, I_{\mathrm{m}}-$ moments of inertia for electric motor and driven machine; $M_{\mathrm{h}}$ - damping moment of coupler; $F, F_{\mathrm{t}}$ - stiffness and damping inter-teeth forces; $M_{\mathrm{tz} 1}, M_{\mathrm{tz} 2}$ - inter-teeth moment of friction, $M_{\mathrm{tz} 1}=T_{1} \rho_{1} ; \quad M_{\mathrm{tz} 2}=T_{1} \rho_{2}$, where $T_{1}$ inter-teeth force of friction (Fig. 7(b)).

Numeric solutions of differential equations are done by CSSP (Continuous System Simulation Program) (Siwicki, 1992) by using England procedure of integration. This is a general procedure of Runge-Kutta type. The procedure assures stability

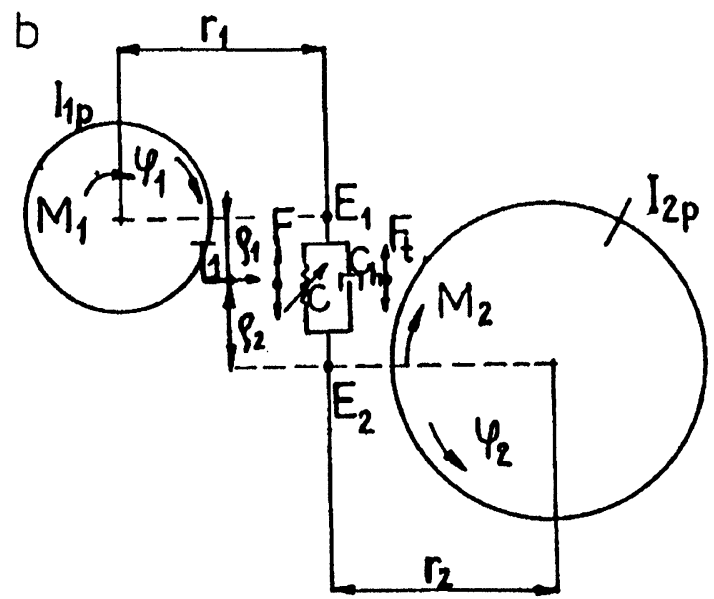

FIGURE 7 Gearbox system. 

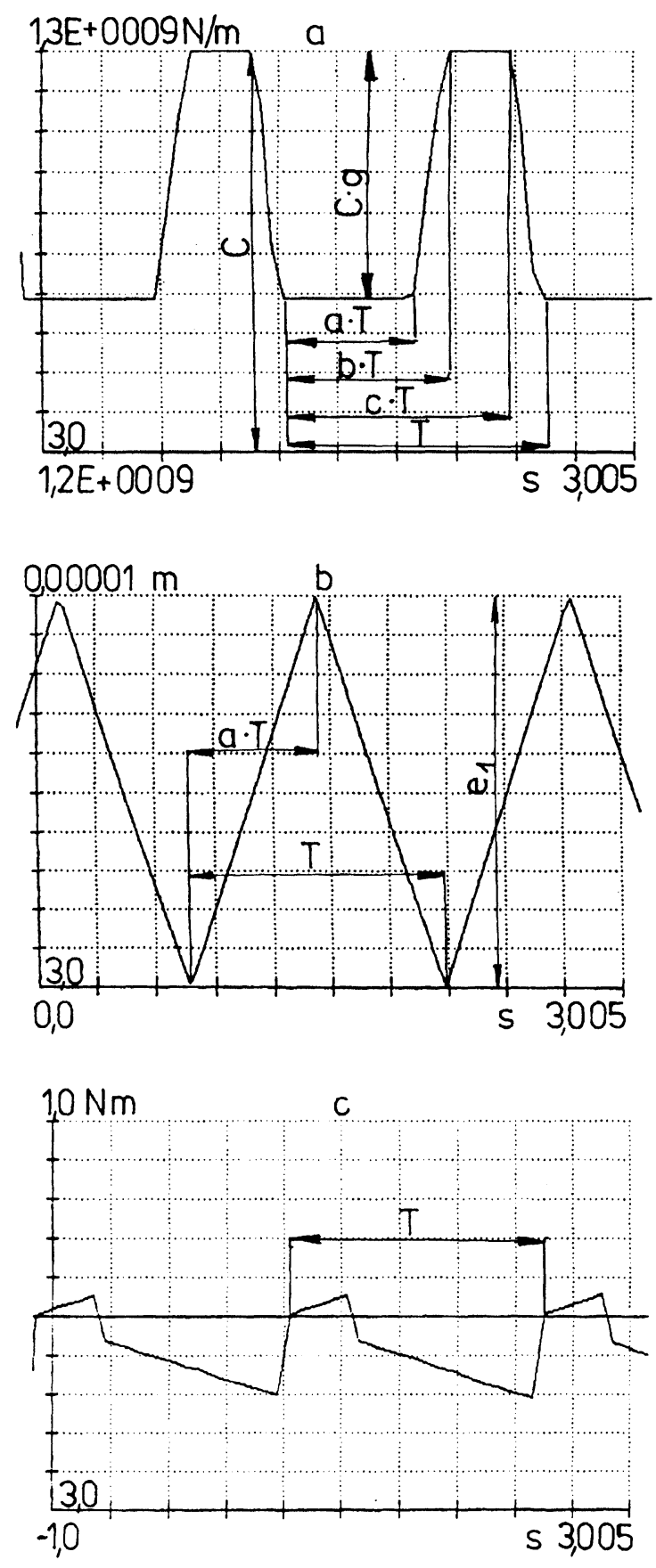

FIGURE 8 (a) Gear stiffness function, $T$ - meshing period, $C$ - gearing stiffness, $(a, b, c, g)$ - parameters of gear stiffness function. (b) Gear error function, $T$ - meshing period, $\left(a, e_{1}\right)-$ parameters of gear error function. (c) Inter-teeth moment of friction function $M_{\mathrm{tz} 1}, T$ - meshing period. of integration even in the case of discontinuity and gives possibility of error estimation and the automatic change of an integration step. Unit CSSPEQ (equation) for inclusion differential equations in PASCAL is used. For example the inter-teeth stiffness force can be written in a form

$$
\begin{aligned}
\mathrm{F}:= & \operatorname{Csz}(\text { pom, } \mathrm{g})^{*}\left(\operatorname { m a x } \left(\mathrm{r} 1^{*} \mathrm{y}[6]-\mathrm{r} 2^{*} \mathrm{y}[7]-1\right.\right. \\
& +\operatorname{Er}(\text { pom, a, e } 1)), \min \left(\mathrm{r} 1^{*} \mathrm{y}[6]-\mathrm{r} 2^{*} \mathrm{y}[7]\right. \\
& +1+\operatorname{Er}(\operatorname{pom}, \mathrm{a}, \mathrm{e} 1), 0)))
\end{aligned}
$$

where Csz(pom,g) - stiffness function; max and min functions are defined as follows:

Function $\min (\mathrm{a}, \mathrm{b}:$ real $)$ : real;

Begin

if $\mathrm{a}<\mathrm{b}$ then $\min :=\mathrm{a}$ else $\min :=\mathrm{b}$

End;

Function max(a, b:real):real;

$$
\begin{aligned}
& \text { Begin } \\
& \text { if } a>b \text { then } \max :=a \text { else } \max :=b
\end{aligned}
$$

End;

r1; r2 - gear base radii; 1 - inter-teeth backlash; $\mathrm{y}[6]=\varphi_{2} ; \mathrm{y}[7]=\varphi_{3} ; \operatorname{Er}($ pom,a,e1 $)$ - error function, where pom $:=\operatorname{frac}\left(y[6]^{*} \mathrm{z} 1 /\left(2^{*} \mathrm{PI}\right)\right)$; a, el - parameters of error function; $z 1$ - number of teeth in a pinion.

\section{RESULTS OF COMPUTER SIMULATIONS}

Controlled factors which were changed for investigating their influence to diagnostic signal are: $C_{\mathrm{s}}-$ clutch/coupler dumping coefficient, $a$ - parameter of the error function (Fig. 8(b)), and $r$ - coefficient of error change (0-1), Eq. (1). Obtained results of computer simulation are interpreted like results obtained by synchronous summation of a diagnostic signal. First set of results of computer simulations is given in Fig. 9. Figure 9(a) gives a picture of $K_{\mathrm{d}}$ function in four different periods: (1) acceleration of a gear system (Fig. 7), from 0 to $980 \mathrm{rpm}$; (2) free rotation; (3) run of the gear system 

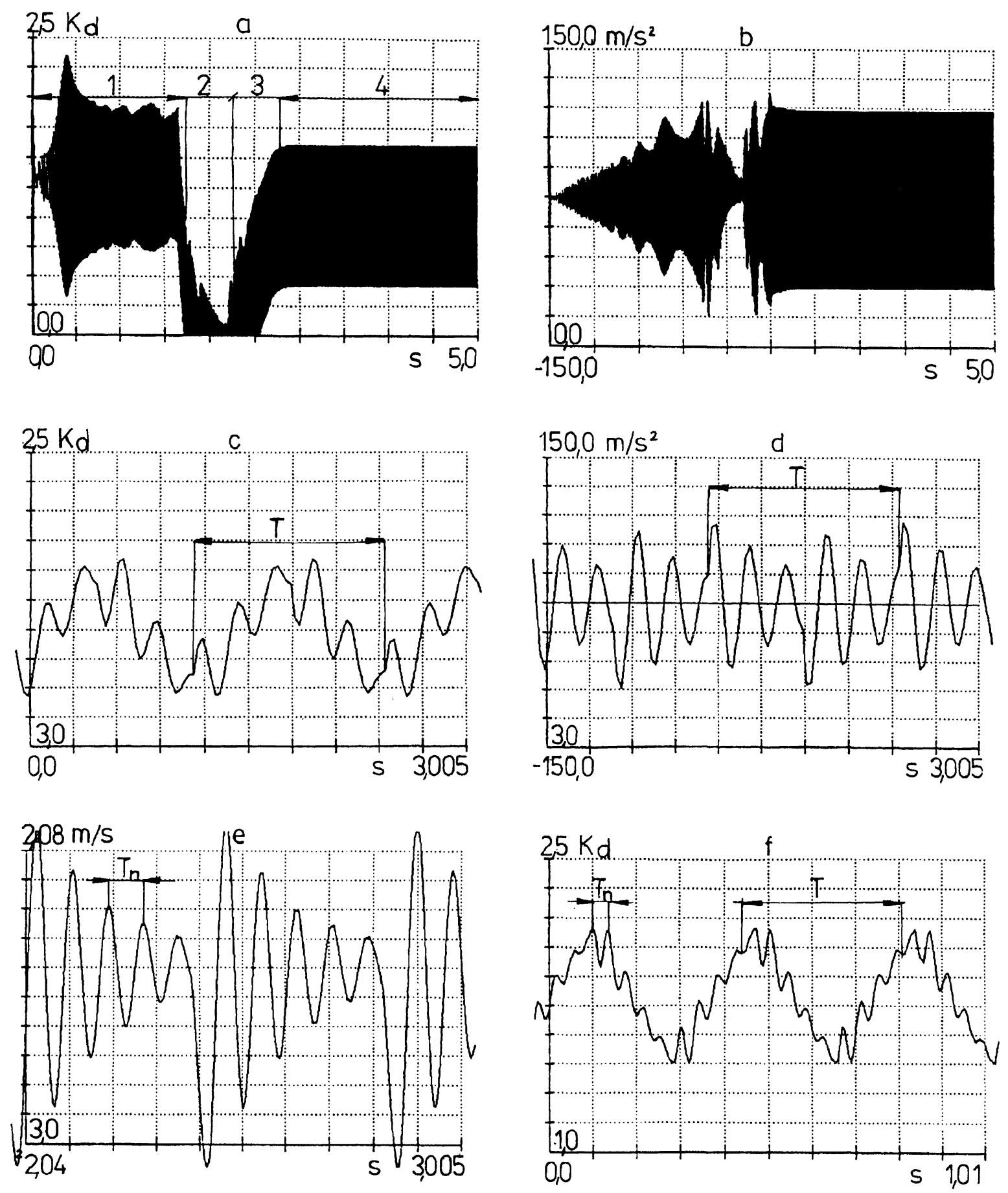

FIGURE 9(a)-(f) 


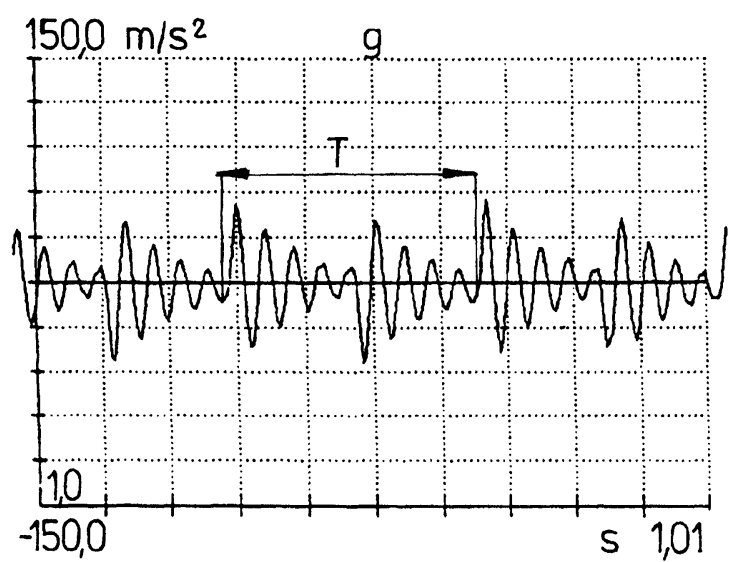

FIGURE $9(\mathrm{~g})$

FIGURE 9 (a) Function of gearing dynamic factor $K_{\mathrm{d}}$, 1 - period of acceleration of gear system from 0 to $980 \mathrm{rpm}$, 2 - period of free rotation, 3 - period of run under linear increase of outer moment, 4 - period of run under constant outer moment. (b) Function of gearing circumference acceleration $\Delta_{\mathrm{a}}$; (c) Zoom of $K_{\mathrm{d}}$, stable run of gearing under steady load, 4th period. (d) Zoom of gearing circumference acceleration function $\Delta_{\mathrm{a}}$, 4th period. (e) Zoom of gearing circumference velocity $\Delta_{v}$, 4th period. (f) Zoom of $K_{\mathrm{d}}$, unstable run of gearing during increasing rotation, 1st period. (g) Zoom of gearing circumference acceleration $\Delta_{\mathrm{a}}, 1$ st period.

under linear increase of outer moment $M_{\mathrm{r}}$; (4) run of the gear system under constant outer moment $M_{\mathrm{r}}$. Inter-teeth forces are the reasons which cause the failure of a gearing. The inter-teeth force reveals all factors which have influence to vibration generated by a gearbox. The forces are transmitted through bearings to an outer housing. A direction of transmission of inter-teeth forces is given in Fig. 7(b) and lies along a line of action $E_{1} E_{2}$. We supposed that if we measure an acceleration on the gearbox housing we may infer on the inter-teeth force's change. It is supposed that the change of the inter-teeth forces is proportional to the difference of acceleration $\Delta_{\mathrm{a}}$ of co-operating gear wheels. The main aim of a computer investigation is presenting differences or similarities between force and acceleration $\Delta_{\mathrm{a}}$. Inter-teeth forces are presented as a ratio $K_{\mathrm{d}}$. Figure 9 (b) gives the acceleration difference $\Delta_{\mathrm{a}}$ in four periods. In Fig. 9 results for the error mode $(0.5 ; 10 ; 0)$ are given. The error mode function is given in Fig. 8(b). Figure 9(c) gives $K_{\mathrm{d}}$ function in 4th period of a gear system run. In Fig. 9(d) $\Delta_{a}$ acceleration is given. One can see similarities between Fig. 9(c) and (d). For the same period of time velocity difference $\Delta_{V}$ is given in Fig. 9(e). There is no direct similarity between inter-teeth force and velocity $\Delta_{\mathrm{v}}$. Inter-teeth force function for 1st period of gearing co-operation is given in Fig. 9(f). The function shows the period of gearing and the period of natural vibration of gearing $T_{\mathrm{n}}$. The function of acceleration $\Delta_{\mathrm{a}}$ for the 1 st period is given in Fig. 9(g). One can see that the error function given in Fig. 8(b) is a cause of two vibration impulses (increase and decrease), so a meshing period $T$ is divided into two periods. It is better seen in acceleration function $\Delta_{\mathrm{a}}$ than in the force function (Fig. 9(f)). Figure 9(c) and (d) does not show full similarity (forces to acceleration), it is supposed that a cause of it is influence of damping moment in the clutch, $M_{\mathrm{h}}$ so for further investigation $C_{\mathrm{s}}=0$ is taken. Figure 10 gives results of these simulations for condition of $C_{\mathrm{s}}=0$. Figure 10(a) gives a course $K_{\mathrm{d}}$ function. Compare Fig. 9(a) with Fig. 10(a). In Fig. 9(a) influence of damping moment $M_{\mathrm{s}}$ is seen. Figure $10(\mathrm{~b})$ gives the zoom of $K_{\mathrm{d}}$ course for $C_{\mathrm{s}}=0$. A zoom course of accelerations $\Delta_{\mathrm{a}}$ presents Fig. 10(c). Figure 10(b) and (c) gives exact similarities of these two courses. Figure 10(d) shows a zoom course of velocity $\Delta_{\mathrm{v}}$ for $C_{\mathrm{s}}=0$ in the 4 th period. Physical quantities of $K_{\mathrm{d}}$ and acceleration $\Delta_{\mathrm{a}}$ for the 1 st period are given in Fig. 10(e) and (f), $C_{\mathrm{s}}=0$. Figure 10(e) shows different main period of a course of $K_{\mathrm{d}}$, compare Fig. 9(f) with Fig. 10(e). Figure 10(e) of accelerations $\Delta_{\mathrm{a}}$ in its course shows a meshing period $T$ of meshing and the gear natural period $T_{\mathrm{n}}$. Figure 11 shows characteristic features of diagnostic signal for an error mode $(0.1 ; 10 ; 0)$. Figure 11 (a) shows an error mode function. Figure 11(b) and (e) shows zooms of inter-teeth forces for 4 th and 1 st period. Figure 11(d) and (f) shows zooms of acceleration $\Delta_{\mathrm{a}}$. The error mode $(0.1 ; 10 ; 0)$ is thought to describe new gearing before run in or at the condition change caused by failure of one bearing supporting gear wheels. At the condition of bearing failure value of $e$ increases either. Compare different courses given in 

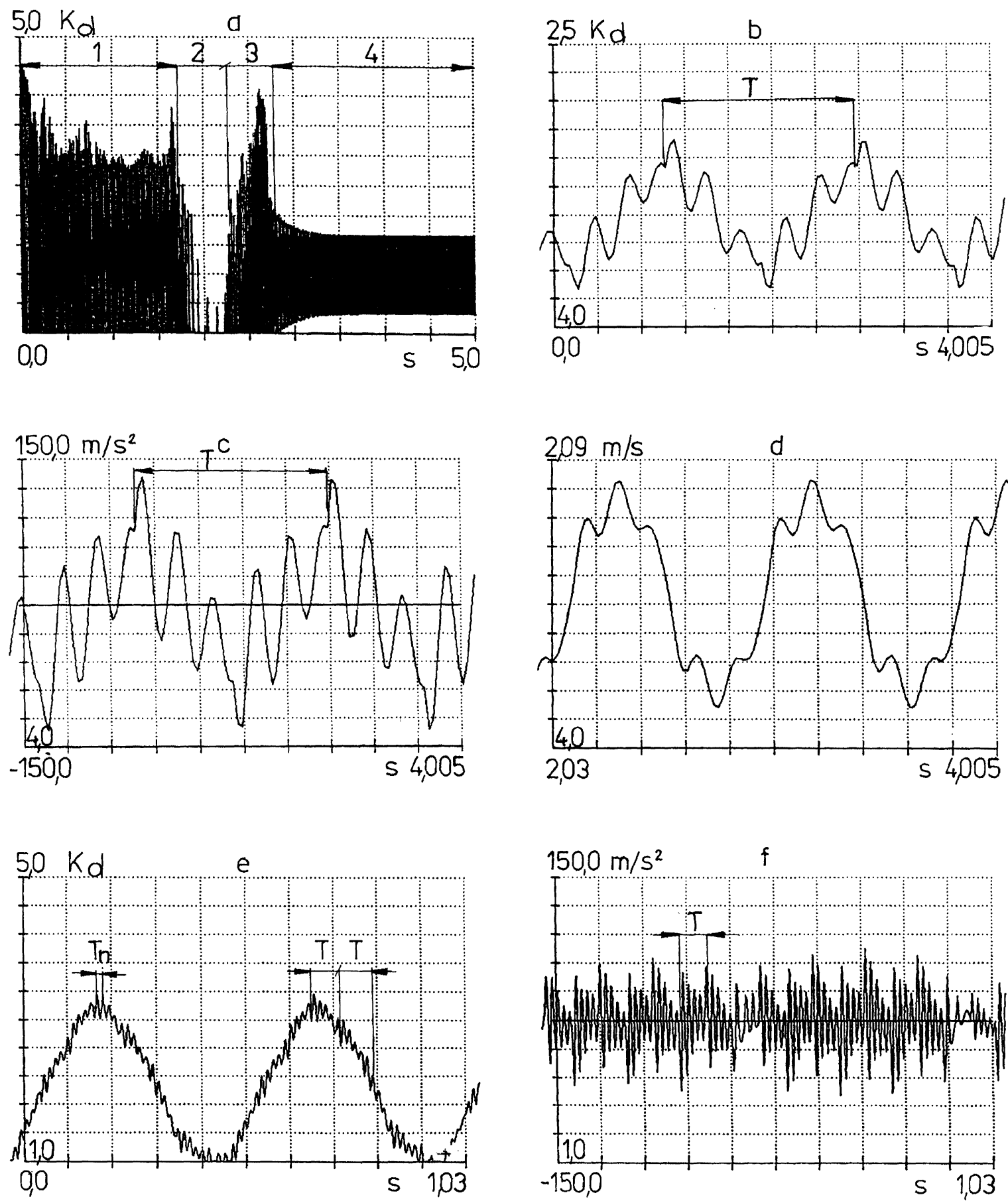

FIGURE 10 (a) Function of gearing dynamic factor $K_{\mathrm{d}}$, clutch damping $C_{\mathrm{s}}=0,1$ - period of acceleration of gear system from 0 to $980 \mathrm{rpm}, 2$ - period of free rotation, 3 - period of run under linear increase of outer moment, 4 - period of run under constant outer moment. (b) Zoom of $K_{\mathrm{d}}$ for $C_{\mathrm{s}}=0$, stable run of gearing under steady load, 4th period. (c) Zoom of gearing circumference acceleration $\Delta_{\mathrm{a}}$ for $C_{\mathrm{s}}=0$, 4th period. (d) Zoom of gearing circumference velocity $\Delta_{\mathrm{v}}$ for $C_{\mathrm{s}}=0$. (e) Zoom of $K_{\mathrm{d}}$ for $C_{\mathrm{s}}=0$, unstable run of gearing during increasing rotation, 1st period. (f) Zoom of gearing circumference acceleration $\Delta_{\mathrm{a}}$, $C_{\mathrm{s}}=0,1$ st period. 

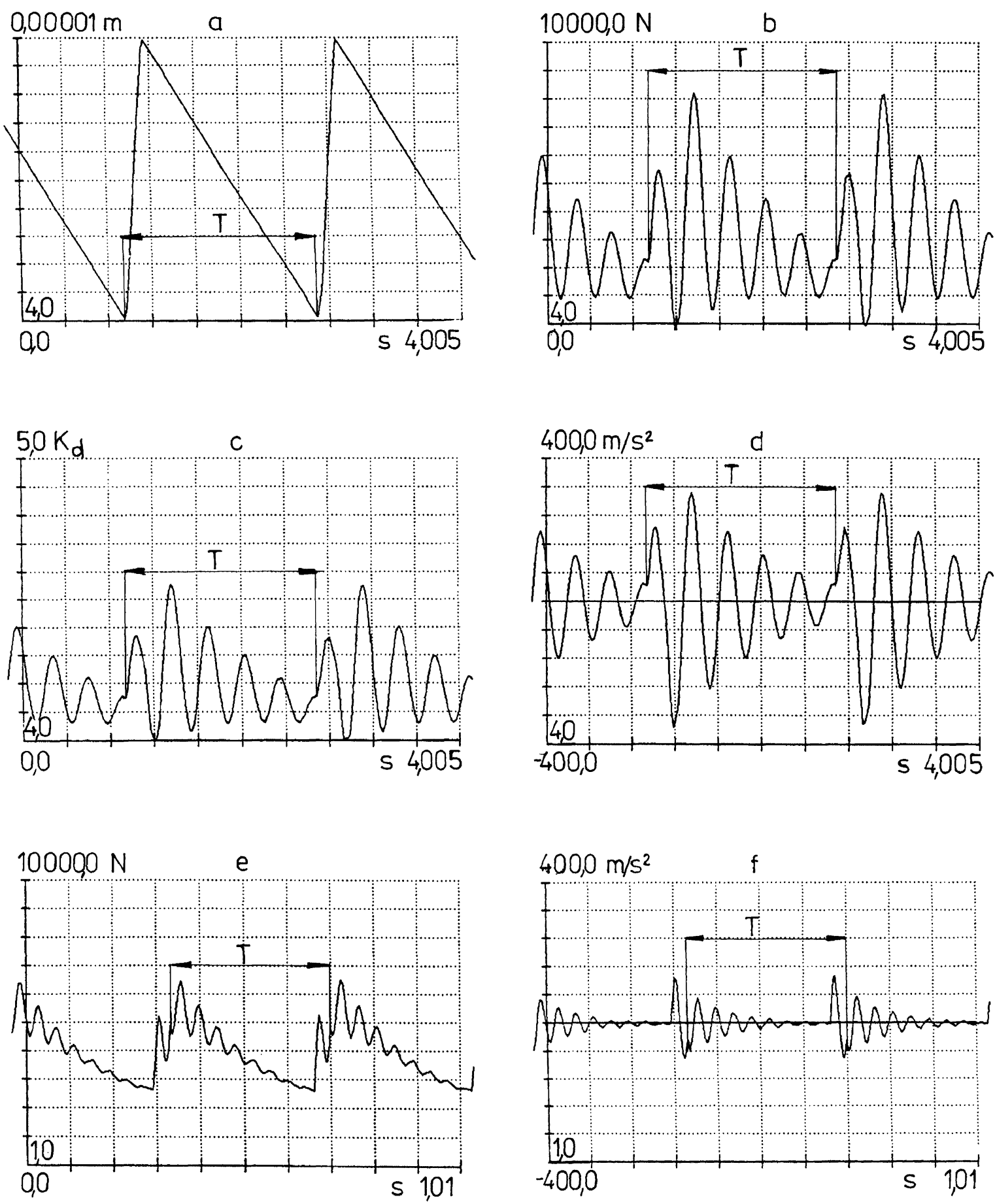

FIGURE 11 (a) Gear error function for error mode $(a ; e ; r)$ (parameter of error function; maximum value of error; coefficient of error change), $(0.1 ; 10 ; 0)$. (b) Zoom of inter-teeth force, parameter of error function $a=0.1$, stable run of gearing under steady load, 4th period. (c) Zoom of gearing dynamic factor $K_{\mathrm{d}}$ function $a=0.1$, 4th period. (d) Zoom of gearing circumference acceleration $\Delta_{\mathrm{a}}, a=0.1$, 4th period. (e) Zoom of inter-teeth forces, $a=0.1$, 1st period. (f) Zoom of gearing circumference acceleration $\Delta_{\mathrm{a}}, a=0.1$, unstable run of gearing during increasing rotation, 1st period. 
Figs. 9(g) and 11(f). The meshing period in Fig. 9(g) is divided into two equal parts $(a=0.5)$ in the error mode, in Fig. 11(f) the machine period is divided in different ways $(a=0.1)$ in the error mode. Deterioration of a gearing causes random change of error function. A depth of error change for simulation of this condition is given by an error mode parameter $r$. Current error is given by Eq. (1). Error functions for $r=0.1 ; 0.3 ; 1$ are given equivalently in Fig. 12(a), (d) and (h). In Bartelmus (1997)
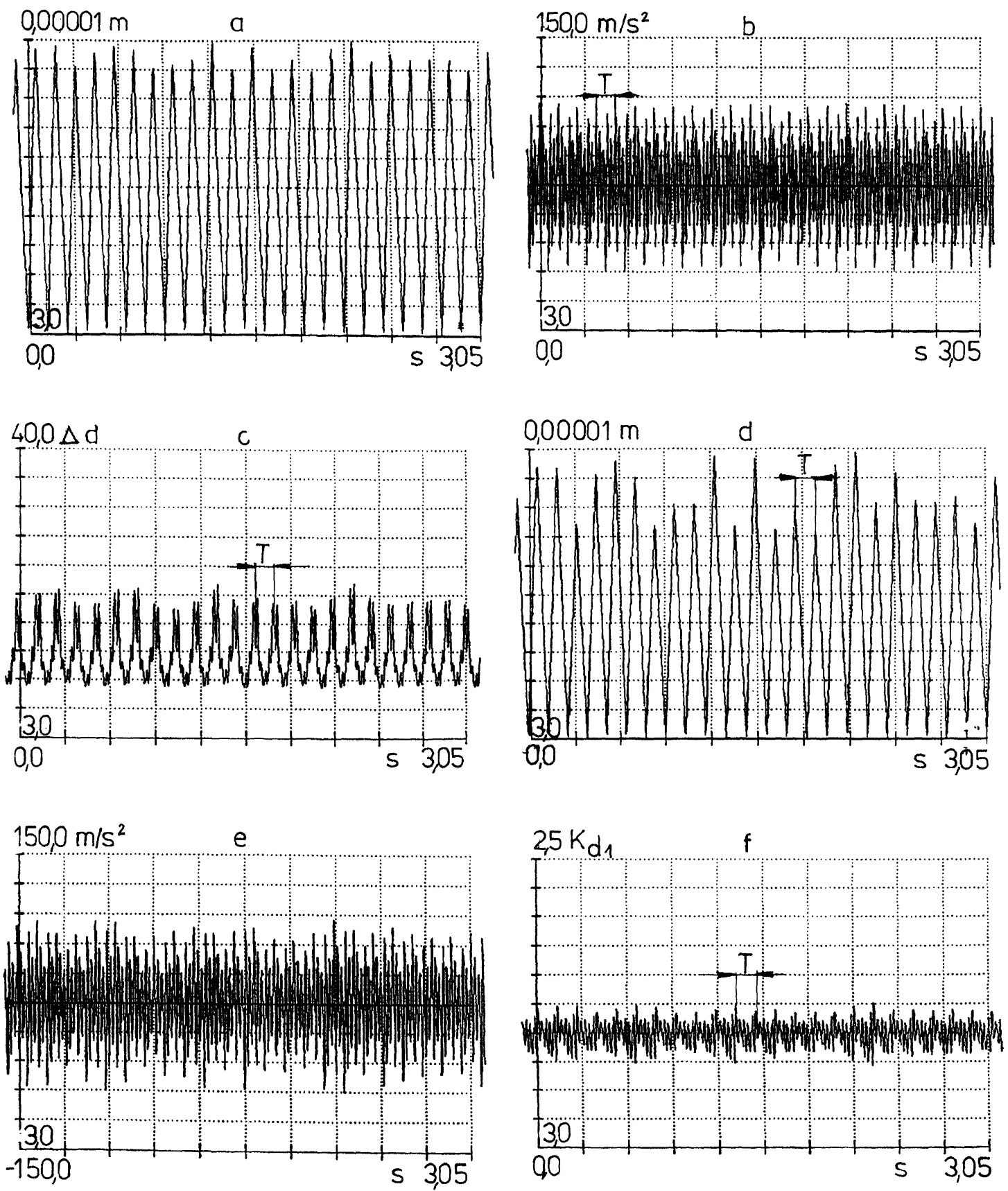

FIGURE 12(a)-(f) 

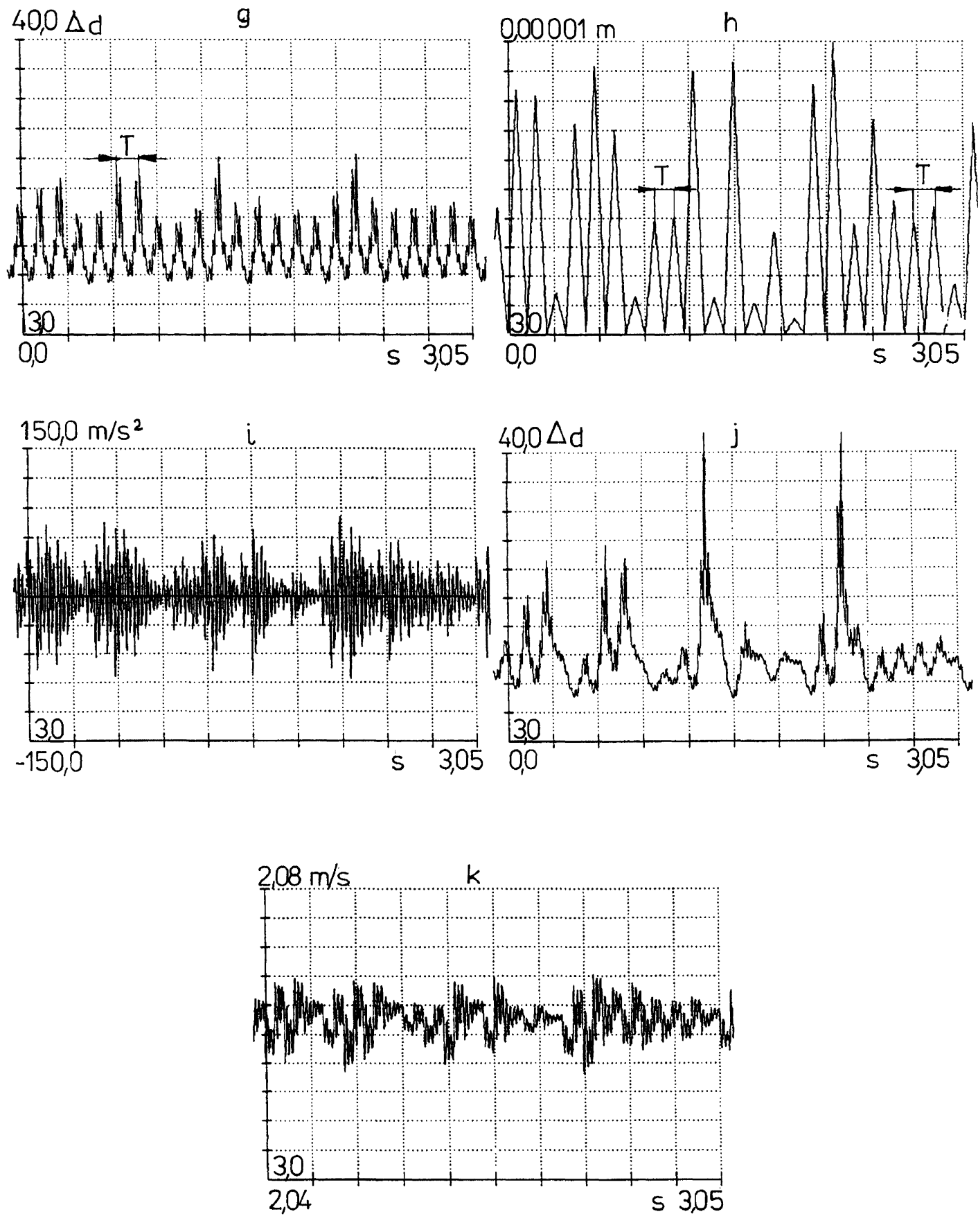

FIGURE 12(g)-(k)

FIGURE 12 (a) Error mode function for $(0.5 ; 10 ; 0.1),(a ; e ; r)$ (parameter of error function; maximum value of error; coefficient of error change). (b) Gearing circumference acceleration function $\Delta_{a}$ for coefficient of error change $r=0.1$, stable run of gearing under steady load, 4th period. (c) Function of acceleration dynamic coefficient $A_{\mathrm{d}}$ for $r=0.1$, th period. (d) Error mode function for $(0.5 ; 10 ; 0.3)$. (e) Gearing circumference acceleration function $\Delta_{\mathrm{a}}$ for $r=0.3$, 4th period. (f) Function of current dynamic factor $K_{\mathrm{d} 1}$ for $r=0.3$, 4th period. (g) Function of $A_{\mathrm{d}}$ for $r=0.3$, 4th period. (h) Error mode function for $(0.5 ; 10 ; 1)$. (i) Gearing circumference acceleration function $\Delta_{\mathrm{a}}$ for $r=1$, 4th period. (j) Function of $A_{\mathrm{d}}$ for $r=1$, 4th period. (k) Gearing circumference velocity function $\Delta_{\mathrm{v}}$ for $r=1$, 4th period. 
some new normalised functions for evaluation of gearing conditions were discussed. The most suitable function was chosen defined as $K_{\mathrm{d} 1}=F(t) /$ $F_{1}(t)$, where $F_{1}(t)$ - measured current force on an input shaft of a gearbox. But for practice there is a need to define equivalent function based on acceleration which are measured on a gearbox housing. For the new condition measure next value is defined as

$$
A_{\mathrm{d}}=\left[A+\left(\Delta_{\mathrm{a}}\right) r_{1}\right] /\left(M_{1}+M_{\mathrm{h}}\right),
$$

where $A_{\mathrm{d}}$ - normalised gearing condition function; $A$ - suitable constant to make the value positive; $\Delta_{\mathrm{a}}$ acceleration; $\left(M_{1}+M_{\mathrm{h}}\right)$ moment on the first shaft; $r_{1}$ - radius of a pinion gear. $A_{\mathfrak{d}}$ function is given for $r=0.1 ; 0.3 ; 1$ in Fig. 12(c), (g) and (j). An example of a function of $K_{\mathrm{d} 1}$ is given in Fig. 12(f) for $r=0.3$. Acceleration functions $\Delta_{\mathrm{a}}$ are given for $r=0.1 ; 0.3 ; 1$ in Fig. 12(b), (e) and (i). One example of a course of velocity function is given in Fig. $12(\mathrm{k})$ for $r=1$. On a base of simulations given in Fig. 12 , a conclusion is drawn that $A_{\mathrm{d}}$ function is very good parameter for condition change identification of a gearing. One of the most important thing in condition monitoring is identification of a fractured or broken tooth. Figure 6 shows a local change of the signal, for one broken tooth one local change of a diagnostic signal. So we may say there is one-to-one mapping. Another evidence for this is given in Fig. $9(\mathrm{~g})$ where a decrease and an increase of a tooth error (Fig. 8(b)) are identified by one impulse in a diagnostic signal. But for an error shape given in Fig. 11(a) an identification of a decrease and an increase of a tooth error is not so clearly identified (Fig. 11(e) and (f)). Taking in mind possibilities of one-to-one identification, further simulation experiments were undertaken. Figure 13 gives a set of results of simulation for one fractured tooth for which a stiffness fall to 0.68 of its normal stiffness. As it is seen from the results of simulation there is very little change of a diagnostic signal given by $K_{\mathrm{d}} ; \Delta_{\mathrm{a}} ; K_{\mathrm{d} 1}$ (Fig. 13(a)(c)). Results of further simulations when stiffness of one tooth in gearing falls to $0.25 \mathrm{C}$ are given in Fig. 14. Figure 14 gives a set of results of computer
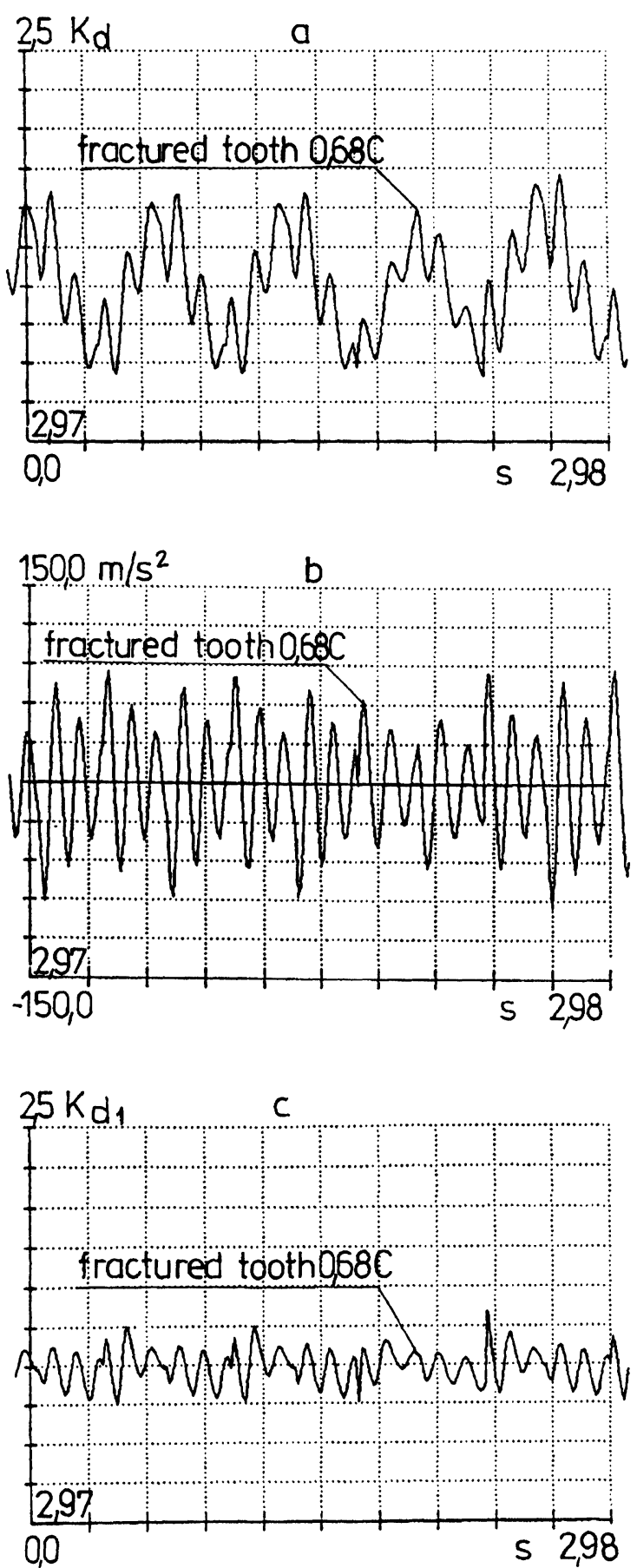

FIGURE 13 (a) Zoom of dynamic factor $K_{\mathrm{d}}$ for gearing stiffness change to $0.68 \mathrm{C}$. (b) Zoom of gearing circumference acceleration $\Delta_{\mathrm{a}}$ for gearing stiffness change to $0.68 C$. (c) Zoom of current dynamic factor $K_{\mathrm{d} 1}$ for gearing stiffness change to $0.68 C$. 

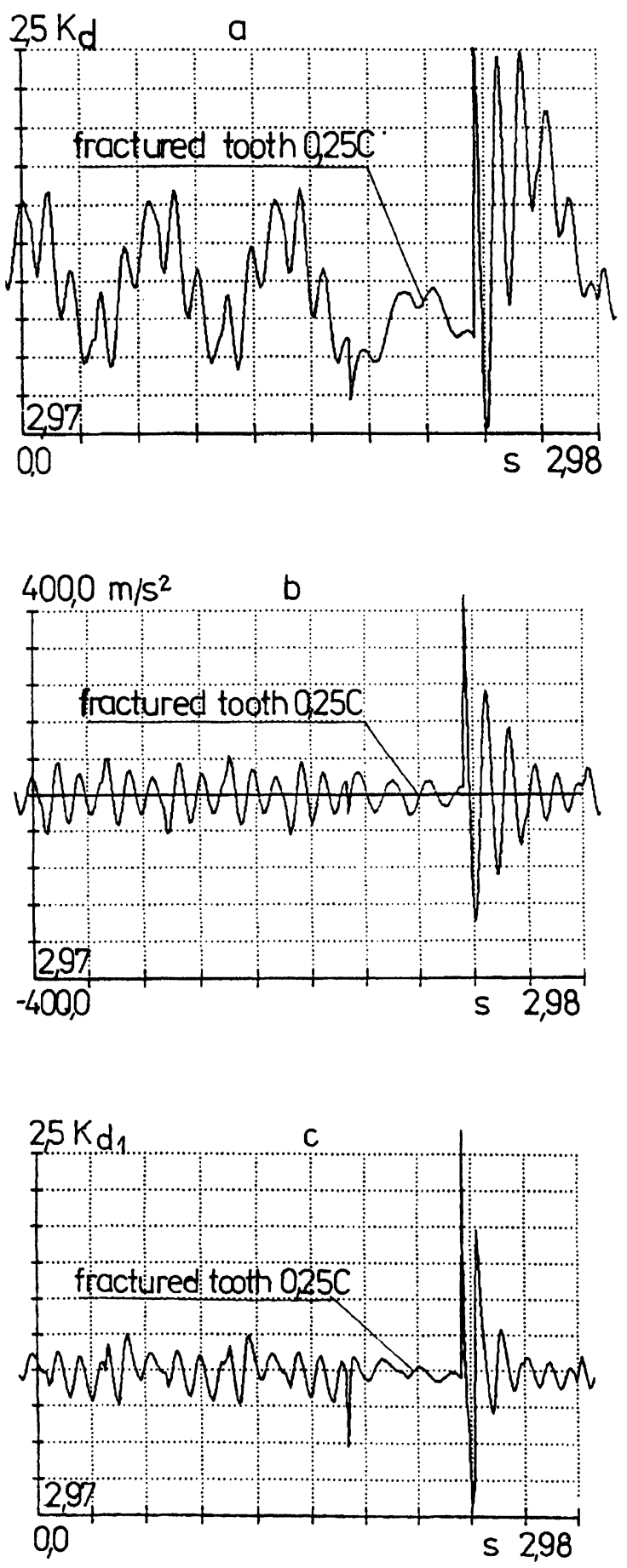

FIGURE 14 (a) Zoom of dynamic factor $K_{\mathrm{d}}$ for stiffness change to $0.25 \mathrm{C}$. (b) Zoom of gearing circumference acceleration function $\Delta_{\mathrm{a}}$ for gearing stiffness change to $0.25 \mathrm{C}$. (c) Zoom of current dynamic factor $K_{\mathrm{d} 1}$ for gearing stiffness change to $0.25 C$. simulations for stiffness change to $0.25 C$. The results show that the change of stiffness to $0.25 C$ gives change of diagnostic signal which may be easy to identify. For further stiffness change to $0.075 C$ results are given in Fig. 15. In Fig. 15(a) and (b) one can see one-to-one mapping (one disturbance in the signal one fractured tooth). In Fig. 15(c) it is seen that one fractured tooth may cause disturbance on several teeth, so there is no one-to-one mapping. It may be stated that $A_{\mathrm{d}}$ function defined by Eq. (6) is very sensitive to condition change but for heavy fracture of a tooth function may be too sensitive. A set of simulation results for a broken tooth is given in Fig. 16. The set presents the equivalent zoom functions for $K_{\mathrm{d}} ; \Delta_{\mathrm{a}} ; K_{\mathrm{d} 1}$, Fig. $16(\mathrm{c})$ does not show one-to-one mapping. Figure 17 gives a set of results of
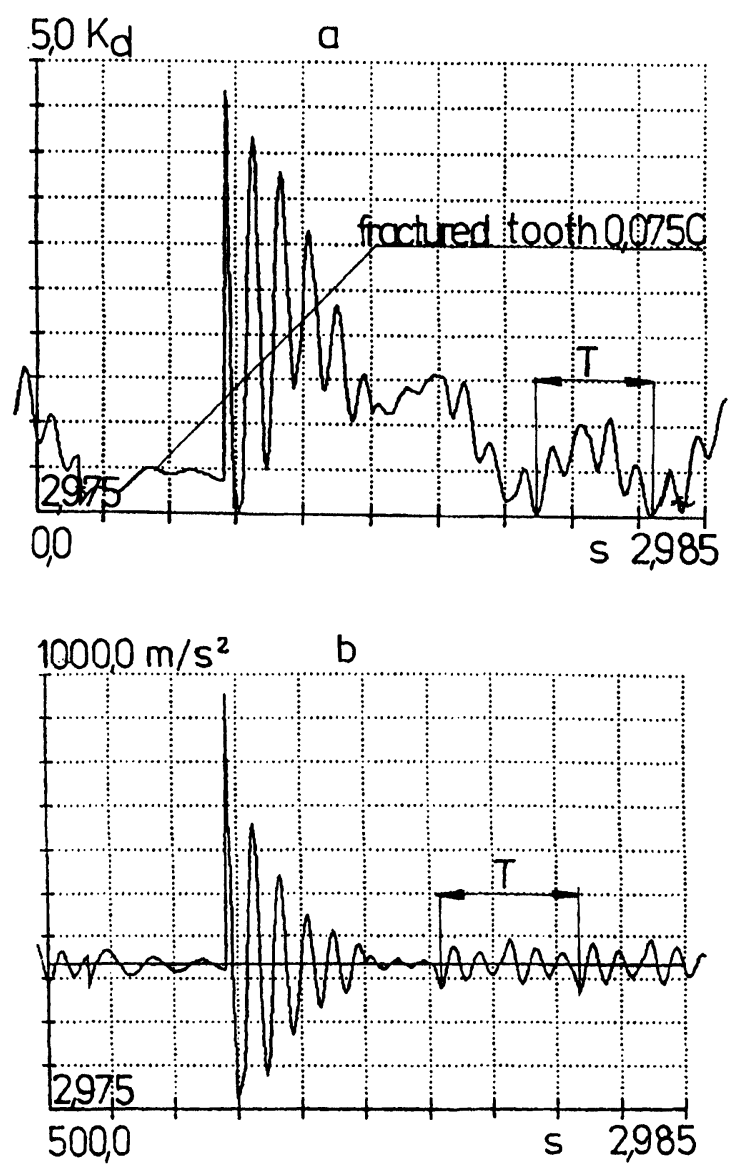

FIGURE 15(a) and (b) 


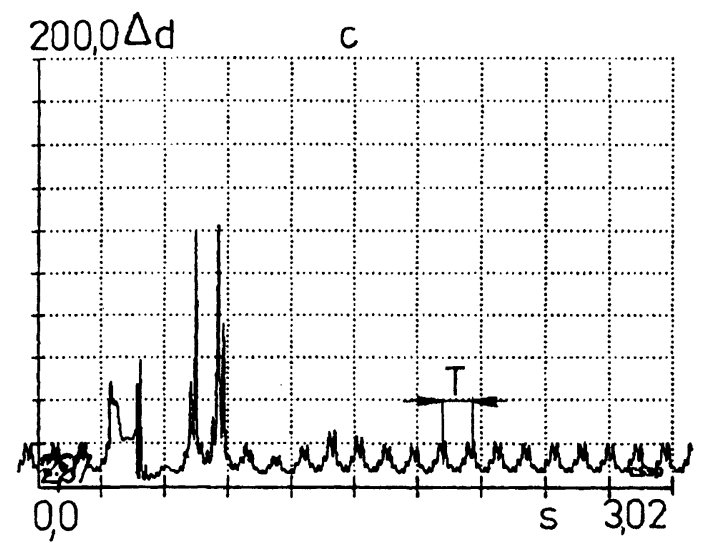

FIGURE 15(c)

FIGURE 15 (a) Zoom of dynamic factor $K_{\mathrm{d}}$ for gearing stiffness change to $0.075 \mathrm{C}$. (b) Zoom of gearing circumference acceleration function $\Delta_{\mathrm{a}}$ for gearing stiffness change to $0.075 C$. (c) Zoom for acceleration dynamic coefficient $A_{\mathrm{d}}$ function for gearing stiffness change to $0.075 C$.
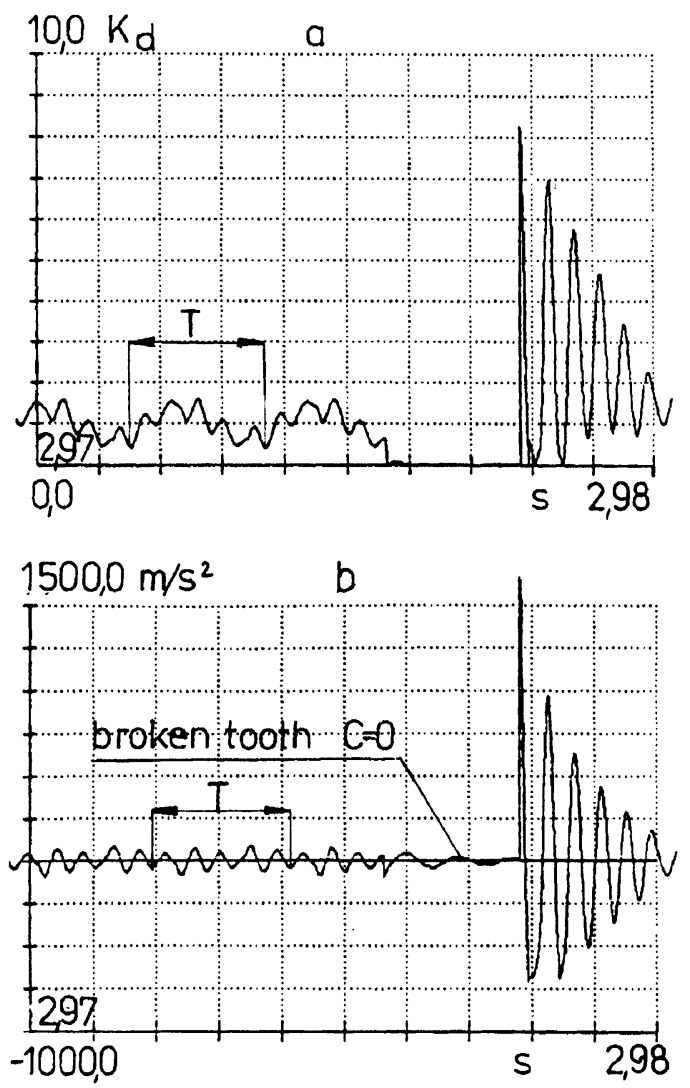

FIGURE 16(a) and (b)

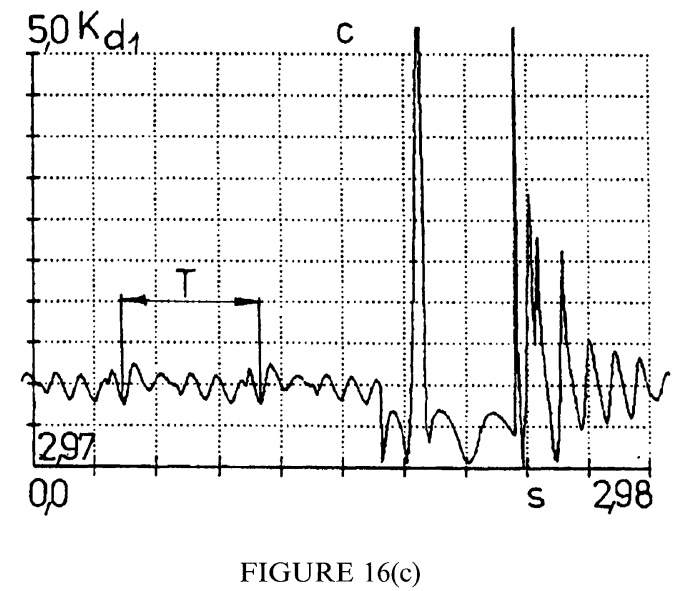

FIGURE 16 (a) Zoom of dynamic factor $K_{\mathrm{d}}$ function for broken tooth. (b) Zoom of gearing circumference acceleration function for broken tooth. (c) Zoom of current dynamic factor $K_{\mathrm{d} 1}$ function for broken tooth.

simulation when one of the tooth has a fault caused by pitting, model of error function is given in Fig. 17(a). Figure 17(c)-(e) shows that there is no one-to-one mapping if diagnostic signal is presented as functions of $K_{\mathrm{d} 1}$ or $A_{\mathrm{d}}$.

\section{CONCLUSIONS}

From the results of computer simulation which are considered as diagnostic signals obtained from synchronous summation detailed features of the signal may be drawn. For example on the basis of results presented in Fig. 2 one may draw a conclusion that an error shape of a tooth taken for investigation by Rettig (see Fig. 1) is as it is given in Fig. 8(b). The same conclusion may be drawn from Fig. 10(c) which gives a diagnostic signal in form of acceleration. From Figs. 9(d) and 10(c) one may draw a conclusion that not only properties of a gearing but also the damping properties of a coupling between an electric motor and a gearbox have influence on a diagnostic signal. One-to-one mapping (one fault one disturbance, in a signal, equivalent for one tooth) does not always hold (see Figs. 15(a) and 16(c)). It seems that this drawback may be eliminated by careful study of evolution/ 

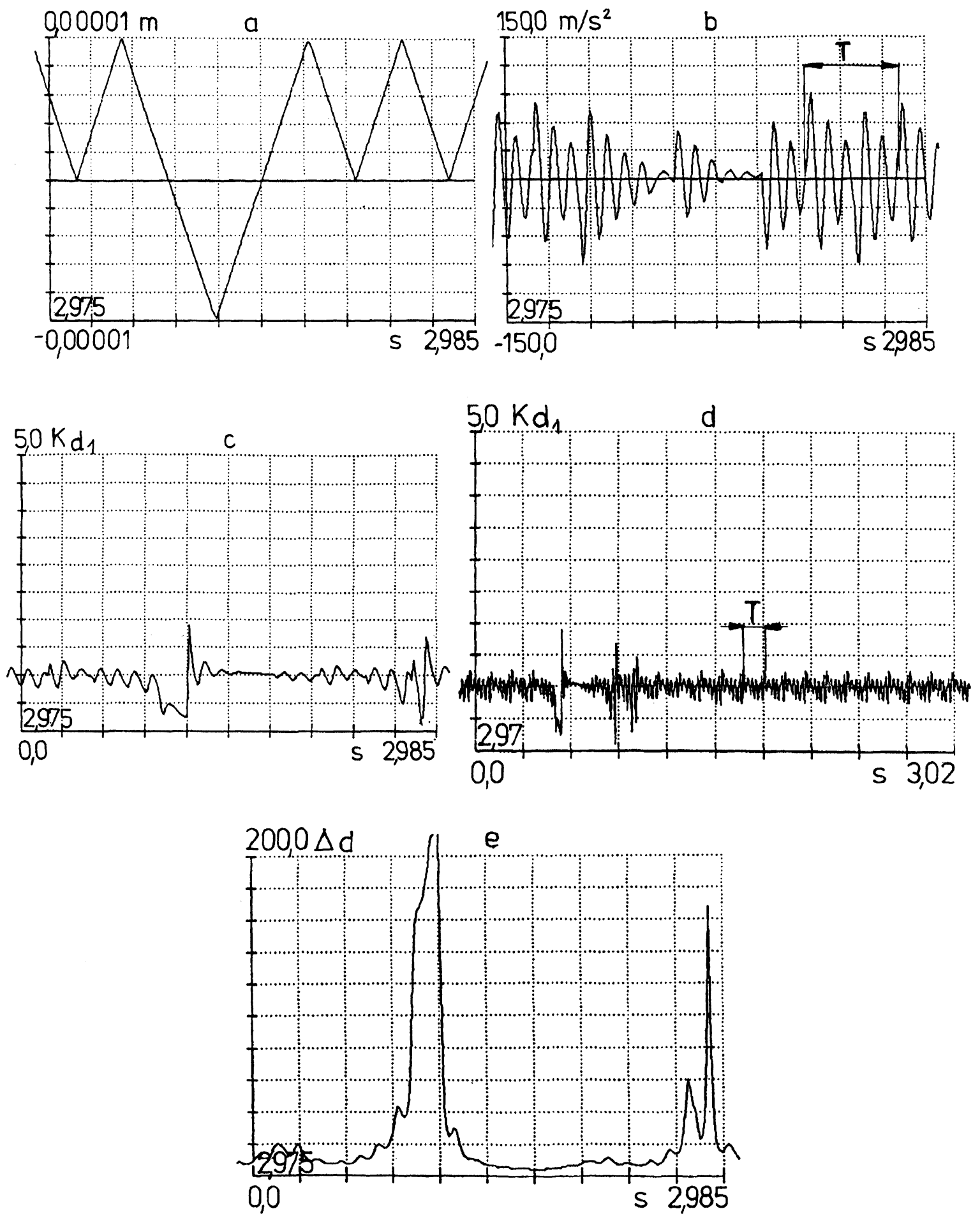

FIGURE 17 (a) Error function for one pitted tooth. (b) Zoom of gearing circumference acceleration function for one pitted tooth. (c) Zoom of dynamic factor $K_{\mathrm{d}}$ function for one broken tooth. (d) Function of current dynamic factor $K_{\mathrm{d} 1}$ for one pitted tooth. (e) Zoom of gearing circumference acceleration function $\Delta_{\mathrm{a}}$. 
development, of a diagnostic signal, as gearing condition changes to avoid misinterpretation. Deterioration of a gearing is described by a change of condition for all teeth in a gearing, models of error modes are given by Fig. 12(a), (d) and (h), and for a single fault, as pitting in one tooth (Fig. 17(a)). The best results of diagnosing the gearing condition change are obtained for signal of acceleration which gives direct measure of inter-teeth forces when a gearbox system runs in steady condition, 4 th period of Fig. 9(a). New gearing condition parameter is suggested, the parameter is denoted as $A_{\mathrm{d}}$ and is given by the formula (6). Mathematical modelling and computer simulation is a very good tool for supporting diagnostic inference. Visualisation of diagnostic signals obtained by computer simulation extends knowledge of a diagnostic expert. The presented results show that from signal presented by synchronous summation it is possible to draw many conclusion on gearing condition not only a broken tooth condition.

\section{NOMENCLATURE}

$a$

\begin{tabular}{|c|c|}
\hline$A_{\mathrm{d}}$ & acceleration dynamic coefficient \\
\hline$b$ & parameter of gearing stiffness \\
\hline$c$ & parameter of gearing stiffness \\
\hline$C, C_{\mathrm{sz}}$ & $\begin{array}{l}\text { gear stiffness, stiffness } \\
\text { function }(\mathrm{N} / \mathrm{m})\end{array}$ \\
\hline$C_{\mathrm{h}}, C_{\mathrm{s}}$ & $\begin{array}{l}\text { damping coefficients } \\
(\mathrm{Nms} \text { or } \mathrm{Ns} / \mathrm{m})\end{array}$ \\
\hline$e, e_{1}$ & parameters of error function \\
\hline $\mathrm{Er}$ & error function \\
\hline$g$ & parameter of gearing stiffness \\
\hline$F, F_{\mathrm{t}}$ & $\begin{array}{l}\text { stiffness and damping inter-teeth } \\
\text { forces }(\mathrm{N})\end{array}$ \\
\hline$I_{\mathrm{s}}, I_{1 \mathrm{p}}, I_{2 \mathrm{p}}, I_{\mathrm{m}}$ & moments of inertia $\left(\mathrm{kg} \mathrm{m}^{2}\right)$ \\
\hline
\end{tabular}

$\begin{array}{ll}K_{\mathrm{d}}, K_{\mathrm{d} 1} & \text { dynamic coefficients } \\ l & \text { inter-teeth backlash }(\mu \mathrm{m}) \\ l_{i} & \text { random coefficient of error } \\ M_{1}, M_{2} & \text { moments of shaft stiffness }(\mathrm{N} \mathrm{m}) \\ M_{\mathrm{tz} 1}, M_{\mathrm{tz} 2} & \text { inter-teeth moments of } \\ & \text { friction }(\mathrm{N} \mathrm{m}) \\ r & \text { coefficient of error change } \\ r_{1}, r_{2} & \text { base gear radius (m) } \\ T & \text { inter-teeth friction force }(\mathrm{N}) \\ \mu & \text { coefficient of friction } \\ \Delta_{\mathrm{a}}, \Delta_{\mathrm{v}} & \text { acceleration and velocity function } \\ & \text { (m/s and m/s) } \\ \varphi_{1}, \varphi_{2}, \varphi_{3}, \varphi_{4} & \text { rotation angels (rad) } \\ \dot{\varphi} & \text { angle velocity }(\mathrm{rad} / \mathrm{s}) \\ \ddot{\varphi} & \text { angle acceleration }\left(\mathrm{rad} / \mathrm{s}^{2}\right) \\ \rho_{1}, \rho_{2} & \text { radius (m) }\end{array}$

\section{References}

Bartelmus, W. (1988) Diagnostic of bevel and cylindrical gears in surface mines, Proceedings of the Second International Symposium on Continuous Surface Mining, Austin, Texas, October 1988, A.A. Balkema Rotterdam, Brookfieled, pp. $131-144$.

Bartelmus, W. (1992) Vibration condition monitoring of gearboxes, Machine Vibration, 1, pp. 178-189, SpringerVerlag London Limited.

Bartelmus, W. (1994) Computer simulation of vibration generated by meshing of toothed wheel for aiding diagnostic of gearboxes, Conference Proceedings Condition Monitoring '94, Swansea, UK, pp. 184-201, Pineridge Press, Swansea, UK.

Bartelmus, W. (1996) Diagnostic symptoms of unstability of gear systems investigated by computer simulation, Proceedings of 9th International Congress, COMADEM 96, Sheffield, pp. $51-61$.

Bartelmus, W. (1997a) Visualisation of vibration signal generated by gearing obtained by computer simulation, Proceedings of XIV IMEKO World Congress, pp. 126-131.

Bartelmus; W. (1997b) Influence of random outer load and random gearing faults to vibration diagnostic signals generated by gearbox systems, Proceedings of 10th International Congress, COMADEM 97, pp. 58-67.

Penter, A.J. (1991) A practical diagnostic monitoring system, Proceedings of an International Conference on Condition Monitoring, Erding, Germany, Pineridge Press, pp. 79-96.

Rettig, H. (1977) Innere Dynamische Zusatzkrafte bei Zahanadgetrieben, Ant. Antriebstechnik, 16(11) (1977), pp. 655663.

Siwicki, I. (1992) Manual for CSSP (in Polish) WARSAW 


\section{ait \\ ENERGY MATERIALS}

M A N E Y publishing

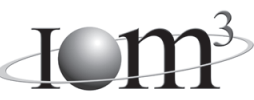

\section{Materials Science \& Engineering for Energy Systems}

Maney Publishing on behalf of the Institute of Materials, Minerals and Mining

The Institute of Materials, Minerals \& Mining

Economic and environmental factors are creating ever greater pressures for the efficient generation, transmission and use of energy. Materials developments are crucial to progress in all these areas: to innovation in design; to extending lifetime and maintenance intervals; and to successful operation in more demanding environments. Drawing together the broad community with interests in these areas, Energy Materials addresses materials needs in future energy generation, transmission, utilisation, conservation and storage. The journal covers thermal generation and gas turbines; renewable power (wind, wave, tidal, hydro, solar and geothermal); fuel cells (low and high temperature); materials issues relevant to biomass and biotechnology; nuclear power generation (fission and fusion); hydrogen generation and storage in the context of the 'hydrogen economy'; and the transmission and storage of the energy produced.

As well as publishing high-quality peer-reviewed research, Energy Materials promotes discussion of issues common to all sectors, through commissioned reviews and commentaries. The journal includes coverage of energy economics and policy, and broader social issues, since the political and legislative context influence research and investment decisions.

\section{CALL FOR PAPERS}

Contributions to the journal should be submitted online at http://ema.edmgr.com

To view the Notes for Contributors please visit: www.maney.co.uk/journals/notes/ema

Upon publication in 2006, this journal will be available via the Ingenta Connect journals service. To view free sample content online visit: www.ingentaconnect.com/content/maney

For further information please contact:

Maney Publishing UK

Tel: +44 (0)113 2497481 Fax: +44 (0)1132486983 Email: subscriptions@maney.co.uk

or

Maney Publishing North America

Tel (toll free): 8662975154 Fax: 6173546875 Email: maney@maneyusa.com

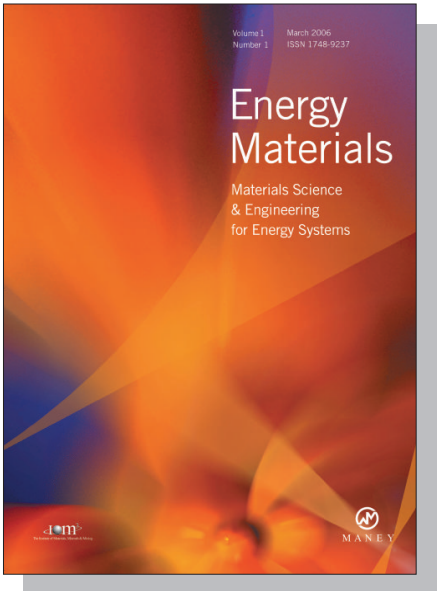

EDITORS

Dr Fujio Abe

NIMS, Japan

Dr John Hald, IPL-MPT, Technical University of Denmark, Denmark

Dr R Viswanathan, EPRI, USA

\section{SUBSCRIPTION INFORMATION}

Volume 1 (2006), 4 issues per year

Print ISSN: 1748-9237 Online ISSN: 1748-9245

Individual rate: $£ 76.00 / U S \$ 141.00$

Institutional rate: $£ 235.00 /$ US $\$ 435.00$

Online-only institutional rate: $£ 199.00 / U S \$ 367.00$

For special $\mathrm{IOM}^{3}$ member rates please email

subscriptions@maney.co.uk

\section{For further information or to subscribe online please visit www.maney.co.uk}



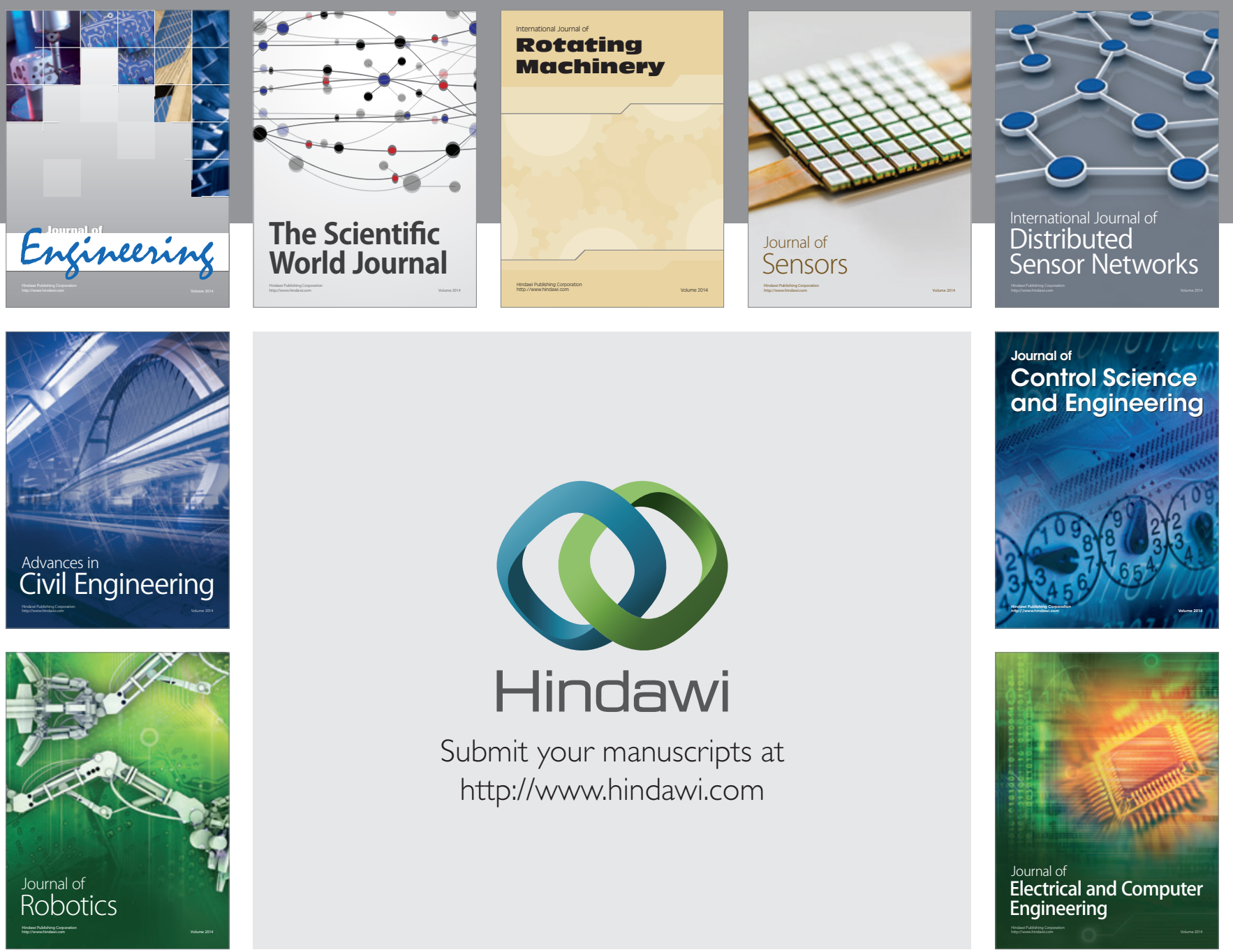

Submit your manuscripts at

http://www.hindawi.com
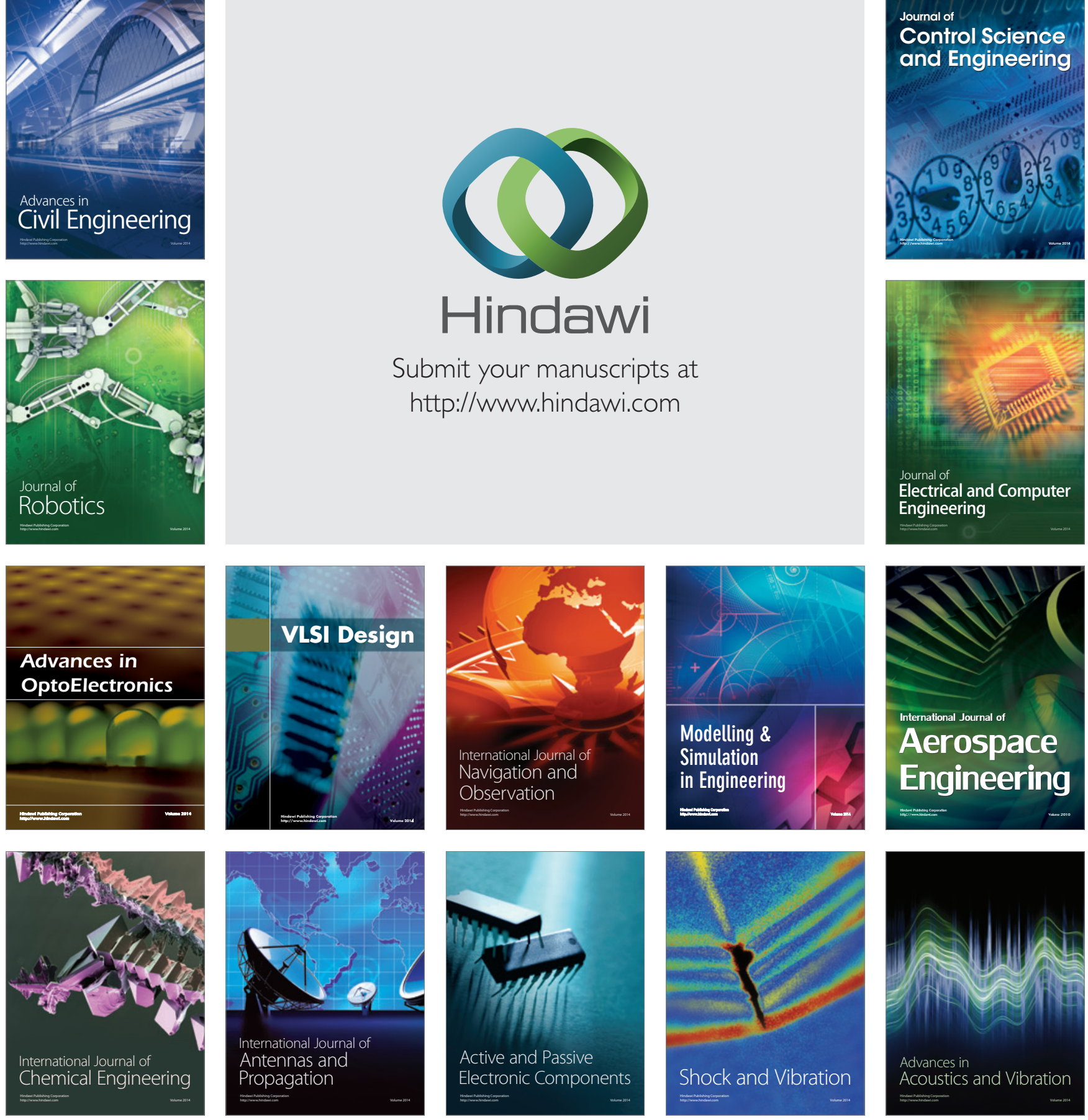